\title{
Research on Influenced Factors about Routing Selection Scheme in Agricultural Machinery Allocation
}

\author{
Fan Zhang $^{1}$, Guifa Teng ${ }^{2, *}$, JieYao $^{3}$, and Sufen Dong ${ }^{1}$ \\ ${ }^{1}$ School of Information Science and Technology, Agricultural University of Hebei, Baoding \\ ${ }^{2}$ Graduate School, Agricultural University of Hebei, PRC \\ tguifa@hebau.edu.cn \\ ${ }^{3}$ Institution of Environmental Protection Research of Baoding
}

\begin{abstract}
Routing allocation scheme is a core issue in agricultural machinery allocation. It is related to the allocation cost, income and timeliness of crop harvest. How to select a farmland spot to harvest, which needs to consider not only the distance between a farmland spot and an agricultural machinery spot, but also road condition, farmland area, types of agricultural machinery and weather conditions. It analyzes the main influenced factors of routing selection solution in agricultural machinery allocation and has built an improved hierarchy analysis model about these influenced factors in this paper. For the uncertain influenced factors or influenced factors with incomplete information, it adopts an improved fuzzy hierarchy analysis method to evaluate the factor weights in the paper. And the resolving power is improved and the believable degree of the routing selection solution is increased. The evaluation model has supplied a good scientific basis for further research.
\end{abstract}

Keywords: Agricultural machinery allocation, hierarchy analysis method, fuzzy consistent matrix.

\section{Introduction}

During harvest time, agricultural machinery users choose proper routing and harvest crops for peasants timely and try to reduce allocation cost and obtain more income, according to crop areas, road conditions, distances of path and so on. How to select a farmland spot to harvest, which needs to consider not only the distance between a farmland spot and an agricultural machinery spot, but also road conditions, farmland areas, types of agricultural machinery and some sudden accidents. The optimal routing solution with lower cost and more economic benefits can be chosen under such factors.

The reasonable allocation solution is the one with shortest distance, the minimum cost and the least to complete the harvest task. It means the allocation routing from agricultural machinery spot to the object farmland spot is affected by more than one target. These targets may be the maximum profits, the minimum allocation risks, the shortest allocation time and so on.

\footnotetext{
* Corresponding author.
} 
Generally, the choice of multi-objective allocation solution may have conflicts between different targets. For example, allocation time is shorter, while the cost will not be little; or the cost is smaller, but the time will not be shortest one.

\section{Description of Allocation Problem}

China is a large agricultural country which has vast territory, complex geographic environment and different natural conditions. Agricultural production has obvious variances about time and region. Some peasants have reaped crops spontaneously in some areas using combine harvester and already have achieved great economic results. However, there are still many problems in agricultural machinery allocation during busy seasons. The peasants don't have proper allocation solution, and then they have to waste much time in changing areas, which has bad effects on oil, human, agricultural machinery, and even farm work may be delayed. On the other hand, road conditions, weather and farmland areas should be considered before agricultural machinery allocation. The routing selection for agricultural machinery allocation is based on these influenced factors in this study.

This paper mainly analyzes six influenced factors, just as follows:

(1)Allocation Time: Crop harvest has timeliness which should be fulfilled in a certain time range. Earlier or later than the time range will increase the allocation costs. So the time is one important factor for agricultural machinery allocation.

(2)Farmland Area: The more farmland areas, the more incomes for agricultural machinery owners.

(3)Allocation Distance: Different allocation schemes have different distances, and the cost for allocation is determined by the allocation distance directly. The less distance, the less allocation cost.

(4)Road Condition: Roads can be divided into several types according to road grades. The different road grade has different influence on allocation time.

(5) Price: Different regions have different harvest price in unit areas, which will directly affect the incomes.

(6)Weather Condition: Weather can impact the allocation time, and then affect the allocation income.

\section{Improved Analytics Hierarchy Process in the Agricultural Machinery Allocation}

As the complexity of objective things and ambiguity of human thoughts, decision-makers are difficult to determine the attribute weights. The incomplete weights information will lead to the uncertainty of solution selection. One method is to analyze the inherent characteristics of objective data by mathematical programming. And the other one depends on subjective judgment of decision-makers completely. While it may cause errors or inconsistent judgment, and the evaluation result may be easily influenced by the understanding level of decision-makers. 


\subsection{Traditional Analytics Hierarchy Process}

AHP (Analytics Hierarchy Process) is one multi-target decision analysis methodology combining with qualitative and quantitative analysis, proposed by T.L.Satty, an American operational research experts in 1970s. AHP can solve decision-making problems with complex structures, many constrained criterions and uneasily be quantized. It can combine with qualitative and quantitative analysis to convert complicated problems into several levels and several parts, and establish a hierarchy structure model. The difficult decision-making problems transform into factors in the same level comparison with each other and build judgment matrix. The weights values of different influenced factors can be obtained through transforming and calculating fuzzy consistent matrix, and supply a scientific basis for the optimal routing solution.

\subsection{Improved Analytics Hierarchy Process}

Traditional AHP is greatly impacted by human subjective judgment and preferences while making decision. This paper introduces fuzzy consistent matrix in the AHP, and overcomes significant differences between consistency of judgment matrix and consistency of human thinking.

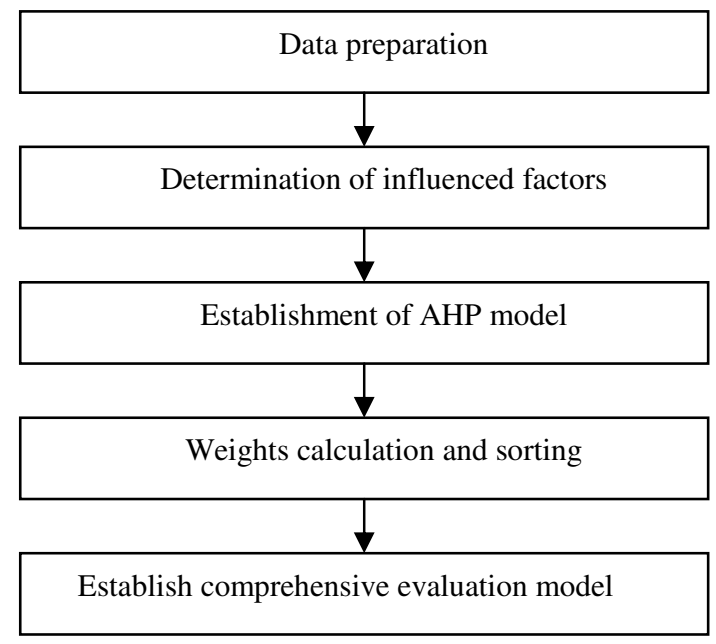

Fig. 1. Flowchart of Influenced factors analysis in the agricultural machinery allocation solution

The sorting method adopted in this paper can increase the resolution of factors important degree, and also can analyze the sensitivity of sorting results with choosing different values for parameter $\alpha$, which will help decision-makers to make optimal decisions [4]. The flow chart of influenced factors analysis about routing selection in the agricultural machinery allocation is shown in figure1. 


\section{Establishment of Comprehensive Evaluation System}

This paper mainly studies on how to optimize allocation routing from the two sides of allocation costs and harvest benefits. The optimal allocation solution is to achieve the lowest allocation cost and the maximum benefits. These influenced factors of agricultural harvest benefit are the capability of agricultural machinery and farmland areas. The influenced factors of agricultural allocation costs are allocation distances, road condition, and weather condition.

\subsection{Establishment of Hierarchy Structure Model}

After the above discussion in section 2, this paper constructs the following AHP structure model.

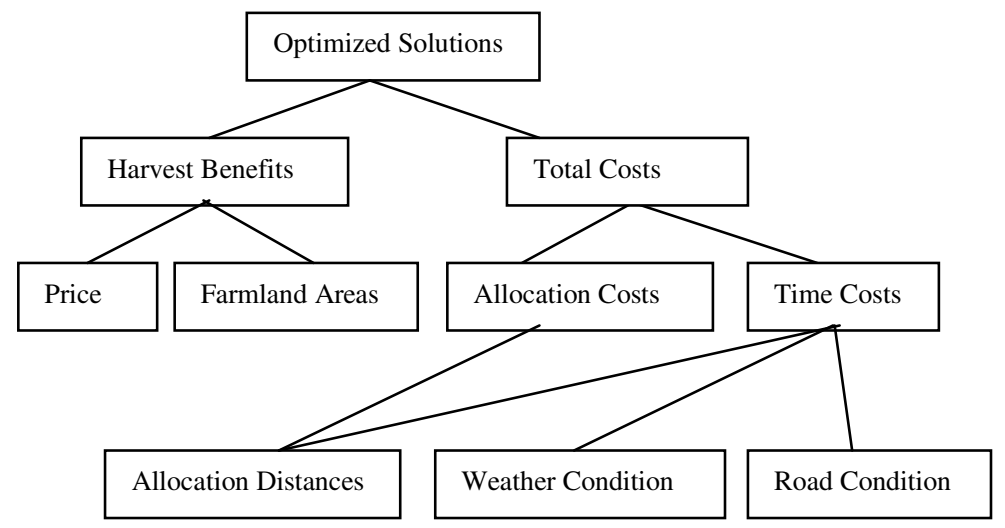

Fig. 2. Hierarchy structure model in agricultural machinery allocation

\subsection{The Construction of Judgment Matrix in Hierarchy Analysis}

Traditional AHP quantifies human judgment, builds judgment matrix and calculates weights values by nine-scale representation method. To a great extent, this method depends on human experiences, and it is difficult to eliminate decision-maker's one-sidedness. In terms of psychological, the classification in the nine-scale representation method is beyond human's judgment. It increases the difficulties of judgment and can supply unreal data easily. According to the existed shortcomings, this paper defines the weights in evaluation system by three-scale hierarchy analysis method.

Table 1. Three-scale representation and meanings

\begin{tabular}{ll}
\hline Scale & Meaning \\
\hline 0 & Factor i is less important than factor $\mathrm{j}$. \\
1 & Factor i is as important as factor $\mathrm{j}$. \\
2 & Factor $\mathrm{i}$ is more important than factor $\mathrm{j}$. \\
\hline
\end{tabular}


After building the hierarchy structure, precedence relation matrix are built in accordance with comparison between factors in two levels. Factors in the same level compare with each other, and then build judgment matrix by three-scale method.

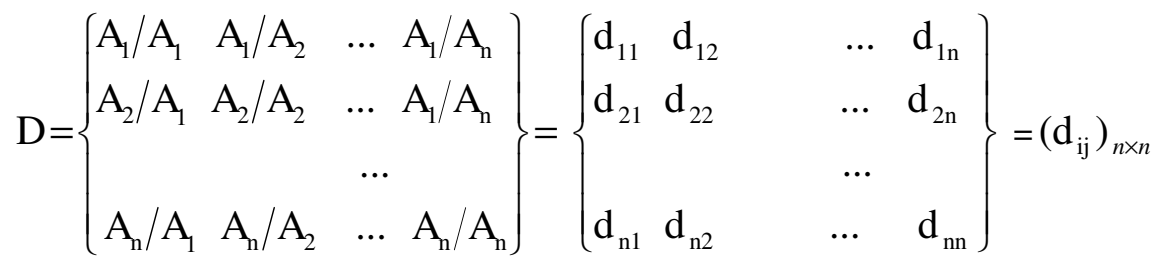

According to the meaning of three scale representation, $\mathrm{d}_{\mathrm{ij}}=0,1,2$

After comparison, the judgment matrix in the first level can be obtained as follow: $D=\left\{\begin{array}{ll}1 & 2 \\ 0 & 1\end{array}\right\}$ the judgment matrix in the second level is as follow: $D_{11}=\left\{\begin{array}{ll}1 & 0 \\ 2 & 1\end{array}\right\}, D_{12}=\left\{\begin{array}{ll}1 & 0 \\ 2 & 1\end{array}\right\}$

The judgment matrix in the third level is as follow: $D_{24}=\left\{\begin{array}{lll}1 & 2 & 2 \\ 0 & 1 & 0 \\ 0 & 2 & 1\end{array}\right\}$.

\subsection{Fuzzy Consistent Matrix}

The traditional AHP method should inspect consistency test of judgment matrix. When it is inconsistent, the judgment matrix should be adjusted to it. So the judgment matrix may be consistent through several times of adjustment and examination. Although some scholars have proposed some improved method, in fact, they are also difficult to realize.

There are two ways to research whether the consistency between judgment matrix and human critical thinking have coordination or not. One is the direct method, and the other one is indirect. In order not to make the problems return to be complicated, which already have simplified, and try to make the decision-making process be closed to actual human thinking process, this paper adopts the indirect method. From the viewpoint of information theory, the consistent problem can be solved by fully using the known judgment information through clever mathematical transformation. In fact, it is impossible to assure that the judgment matrix has complete consistency, especially for multi-target problems. However, the requirement should be broadly consistent.

The consistent test criterion of judgment matrix is just empirical data and lack of scientific and effective certification. So the fuzzy consistent matrix is introduced to solve consistent test problem in this paper.

\subsubsection{Definition of Fuzzy Consistent Matrix}

Definition 1. If Matrix $\mathrm{R}=\left(\mathrm{r}_{\mathrm{ij}}\right)_{n \times n}$, meets: $0 \leq r_{i j} \leq 1,(\mathrm{i}, \mathrm{j}=1,2, \ldots, \mathrm{n})$, so $\mathrm{R}$ is called fuzzy matrix[1]. 
Definition 2. If fuzzy matrix $\mathrm{R}=\left(\mathrm{r}_{\mathrm{ij}}\right)_{n \times n}$ meets, $\forall \mathrm{i}, \mathrm{j}, \mathrm{k}, r_{i j}=r_{i k}-r_{j k}+0.5$, so fuzzy matrix $\mathrm{R}$ is called fuzzy consistent matrix[1].

\subsubsection{Conversion of Fuzzy Judgment Matrix}

After normalized the judgment matrix $\mathrm{R}=\left(r_{i j}\right)_{n \times n}$, it sums by rows, which be denoted as $r_{i}=\sum_{j=1}^{n} r_{i j}$. $(\mathrm{i}=1,2, \ldots, \mathrm{n})$. The conversion formula is as follow: $r_{i j}^{\prime}=\frac{r_{i}-r_{j}}{2 n}+0.5$. Using it, the matrix $R$ can be converted into fuzzy consistent matrix D.

Compared to the traditional Analytical Hierarchy Process, Fuzzy Analytical Hierarchy Process has the following advantages.

(1) Compared with testing whether the judgment matrix has the consistency through calculating its largest eigenvalue and its corresponding eigenvector, it is easier for fuzzy AHP to test whether the fuzzy matrix has the consistency.

(2) The fuzzy inconsistent matrix elements can be adjusted to be consistent quickly, and the weak point,which is the complicate judgment process with several adjustment and inspection, can be overcome by Fuzzy Analytical Hierarchy Process method.

(3) The matrix consistency criterion of fuzzy AHP is more scientific, accurate and simple than the traditional one.

Fuzzy consistent matrix meets consistent condition, so matrix D never need to consistent test. Judgment matrix $\mathrm{R}$ is converted into fuzzy consistent matrix D:

$$
\begin{aligned}
D & =\left\{\begin{array}{ll}
0.5 & 0.75 \\
0.25 & 0.5
\end{array}\right\}, D_{11}=\left\{\begin{array}{ll}
0.5 & 0.25 \\
0.75 & 0.5
\end{array}\right\}, D_{12}=\left\{\begin{array}{ll}
0.5 & 0.25 \\
0.75 & 0.5
\end{array}\right\} \\
D_{24} & =\left\{\begin{array}{lll}
0.5 & 0.833 & 0.667 \\
0.167 & 0.5 & 0.333 \\
0.333 & 0.667 & 0.5
\end{array}\right\}
\end{aligned}
$$

\subsection{Weights of Influenced Factors and Sorting}

The factors weight value of the level in the fuzzy consistent matrix is calculated by the following formula in the paper [1].

$$
\begin{aligned}
& \omega_{\mathrm{i}}=\frac{1}{\mathrm{n}}-\frac{1}{2 \alpha}+\frac{\sum_{j=1}^{\mathrm{n}} r_{i j}^{\prime}}{\mathrm{n} \alpha}, \mathrm{i}=1,2, \ldots, \mathrm{n}, \mathrm{n} \text { is the amount of factors. } \alpha \text { Should meet } \\
& \alpha \geq \frac{n-1}{2} .
\end{aligned}
$$


$\alpha$ is a kind of measure about objects difference degree that perceived by people. This formula has flexibility. The bigger the value of $\alpha$, the smaller difference of weighs; meanwhile the smaller the value of $\alpha$, the bigger difference of weighs. When $\alpha=\frac{n-1}{2}$, the weight difference can achieve to the biggest value. Therefore, the smaller value of $\alpha$ indicates that decision-makers may pay more attentions on the difference of important degree between elements [3]. After experiment in this paper, the value of $\alpha$ in the first level is chosen as 3 , the value of $\alpha$ in the second level is chosen as 4 . The weight values can be calculated as follows.

$$
\begin{aligned}
& \omega=(0.625,0.375), \omega_{11}=(0.375,0.625), \omega_{12}=(0.375,0.625) \\
& \omega_{24}=(0.417,0.250,0.333)
\end{aligned}
$$

\subsection{Foundation of the Comprehensive Evaluation Model}

The comprehensive evaluation model is based on the hierarchy structure model of agricultural machinery allocation. After comparing the importance of factors and calculating the weight value of factors in the level, sorting is from the bottom up. Then weights value in the evaluation model of the optimal routing solution will be obtained.

In accordance with agricultural machinery allocation, the evaluation model is founded as follow. $\mathrm{M}=\sum_{i=1}^{n} \omega_{i} C_{i} . C_{i}$ stands for $\mathrm{i}^{\text {th }}$ influenced factor, $\omega_{i}$ means the weight value of $i^{\text {th }}$ factor to the object in previous level.

After discussion, the model is shown in the following tables.

Table 2. The influenced factors and weight values of Time Cost

\begin{tabular}{cccc}
\hline Factor & Allocation Distance & Weather Condition & Road Condition \\
\hline Time cost & 0.417 & 0.250 & 0.333 \\
\hline
\end{tabular}

Table 3. The influenced factors and weight values of Total Cost

\begin{tabular}{lll}
\hline Factor & Allocation Cost & Time Cost \\
\hline Total Costs & 0.625 & 0.375 \\
\hline
\end{tabular}

Table 4. The influenced factors and weight values of Allocation Cost

\begin{tabular}{lll}
\hline Factor & Farmland Areas & Price \\
\hline Allocation Benefit & 0.625 & 0.375 \\
\hline
\end{tabular}

Combing with Table 2, Table 3, Table 4, Table 5 and Hierarchy structure model in section 4 , the final optimization routing scheme can be expressed in Table 6 . 
Table 5. The influenced factors and weight values of Routing Optimization Scheme

\begin{tabular}{lll}
\hline Factor & Allocation Benefit & Total Costs \\
\hline Routing Optimization Scheme & 0.625 & 0.375 \\
\hline
\end{tabular}

Table 6. The influenced factors and weight values of Routing Optimization

\begin{tabular}{llllll}
\hline Factor & $\begin{array}{l}\text { Farmland } \\
\text { Areas }\end{array}$ & Price & $\begin{array}{l}\text { Allocation } \\
\text { Distance }\end{array}$ & $\begin{array}{l}\text { Weather } \\
\text { Condition }\end{array}$ & $\begin{array}{l}\text { Road } \\
\text { Condition }\end{array}$ \\
\hline $\begin{array}{l}\text { Routing } \\
\text { Optimization }\end{array}$ & 0.391 & 0.234 & 0.293 & 0.035 & 0.047 \\
\hline
\end{tabular}

So Routing Optimization $=0.391 \times_{\text {farmland areas }+} 0.234 \times_{\text {price }} 0.293 \times$ allocation distance $+0.035 \times$ weather condition $+0.047 \times$ road condition.

Seen from the above tables, the influenced weights of road condition, allocation distance, machinery types, farmland areas and sudden accidents, which are achieved by methods in the paper, supply a good theoretical support.

\section{Conclusions}

This paper mainly discusses the influenced factors in agricultural machinery allocation, and analyzes the effects that the factors by improved AHP method under the circumstances of uncertain influenced factors or influenced factors with incomplete information. The formula for calculating and sorting the weight values of factors, which is adopted in this paper, can supply higher resolution when amount of factors is big and has better flexibility and practicality. This paper proposes a good decision-making idea for routing solution about agricultural machinery allocation. And it also supplies a better scientific basis for further research.

\section{References}

1. Lv, Y., Guo, X., Shi, W.: A New Way for Improving Consistency of the Fuzzy Complementary Judgment Matrices, vol. 16, pp. 55-59 (2007) (in Chinese)

2. Zhan, J.: The Research on Scale in AHP. Guangxi University (2005) (in Chinese)

3. Lan, J.: Research on Priorities of Analytic Hierachy Process and Problems of Fuzzy Multiple Attribute Decision Making. Southwest Jiaotong University (2006) (in Chinese)

4. Wang, Z.: Research on Evaluating Urban Expressway Construction Risk Based on Fuzzy Analytic Hierarchy Process. Tianjin University of technology (2009) (in Chinese)

5. Zhu, W., Hu, A.: Emergency Logistics Selecting Scheme with AHP. Logistics Technology 3, 45-47 (2005) (in Chinese)

6. Chu, M.: The construction problems of Judgment Matrices in Analytic Hierarchy Process. Nanjing technology University (2005) (in Chinese)

7. Singh, G., Pathak, B.K.: A decision support system for mechanical harvesting and transportation of sugarcane in Thailand. Computers and Electronics in Agriculture 11, 173-182 (1994) 
8. Hetz, E.J., et al.: Optimization of Machinery System. Agricultural mechanization in Asia, Africa and Latin America 17(1), 68-76 (1986)

9. Edwards, W., Boehlje, M.: Machinery selection considering timeliness losses. Transactions of the ASAE 23(4), 810-815, 821 (1980)

10. Singh, Dvindar, Holtman, J.B.: An heuristic agricultural field machinery selection algorithm for multi-crop farms. Transactions of the ASAE 22(4), 763-770 (1979)

11. Rotz, C.A., Muhtar, H.A., Black, J.R.: A multiple crop machinery selection algorithm. Transactions of ASAE 26(6), 1644-1649 (1983)

12. $\mathrm{Wu}, \mathrm{J} .:$ Study on some problem in multiple attribute decision making based on interval complementary judgment matrices. Southwest Jiaotong University doctor degree dissertation (2004) (in Chinese)

13. Liang, X., Yin, C.: A Method of Determining Fuzzy Matrix Weight. Journal of Xi, an University of Arts \& Science (Natural Science Edition) 1 (2010) (in Chinese)

14. Zhan, J., Lu, Y.: Least Square Method for Sequencing Judgment Matrix of Interval Numbers. Journal of Huaqiao University (Natural Science) 1 (2005) (in Chinese)

15. Zhang, Q.: Research on Performance Appraisal of Green Supply Chain with fuzzy AHP. Tianjin Normal University (2009) (in Chinese) 